\title{
IMPLEMENTASI E-COMMERCE BERBASIS CONTENT MANAGEMENT SYSTEM PADA SEPOKATSEPATU
}

\author{
Mochammad Farhan Hutama ${ }^{1)}$, Yudi Santoso ${ }^{2)}$ \\ ${ }^{1}$ Sistem Informasi, Fakultas Teknologi Informasi, Universitas Budi Luhur \\ ${ }^{1,2} \mathrm{Jl}$. Raya Ciledug, Petukangan Utara, Kebayoran Lama, Jakarta Selatan 12260 \\ E-mail : farhanhutama@gmail.com ${ }^{1)}$, yudi.santoso@budiluhur.ac.id ${ }^{2)}$
}

\begin{abstract}
Abstrak
E-commerce merupakan salah satu teknologi yang berkembang pesat dalam dunia internet khususnya pada bidang pemasaran. E-commerce merupakan cara baru dalam dunia informasi, karena dapat memberikan informasi dalam bentuk yang lebih menarik dan dapat diakses setiap saat secara online. Sepokatsepatu yang bergerak dibidang penjualan sepatu. Menjual berbagai macam jenis sepatu dari sepatu casual, sport maupun running. Kurangnya luasnya pemasaran produk dan kurangnya informasi ketersediaan sepatu menyebabkan pelanggan mengurungkan niatnya untuk membeli di sepokatsepatu yang berdampak pada turunnya pendapatan. Untuk membantu permasalah tersebut maka dibuatlah website e-commerce berbasis CMS (Content Management System). Pendekatan yang digunakan penulis yaitu wawancara, observasi, dan studi literatur. Yang dihasilkan dari penelitian ini adalah website berbasis CMS (Content Management System) yang diharapkan dapat membantu meningkatkan pendapatan, lebih mudah mencari informasi produk dan memperluas jangkauan penjualan. Pada penulisan ini penulis mengambil judul "Implementasi E-commerce berbasis CMS (Content Management System) pada Sepokatsepatu”.
\end{abstract}

Kata kunci: website, e-commerce, content management system, sepokatsepatu

\section{PENDAHULUAN}

E-Commerce ialah proses jual beli produk secara elektronik atau online untuk konsumen, perusahaan ke perusahaan dengan komputer sebagai penghubung transasksi bisnisnya.[1] E-commerce merupakan cara baru dalam dunia informasi dalam bidang pemasaran.

Tujuan penulisan ini yaitu :

a. Dengan adanya website e-commerce dapat meningkatkan jumlah penjualan dan memperluas pemasaran produk.

b. Dengan adanya website e-commerce diharapkan dapat mempermudah pelanggan untuk dapat melihat ketersediaan produk sepatu.

Masalah yang ada di Sepokatsepatu yaitu :

a. Pemasaran produk yang kurang luas, yang dapat menyebabkan menurunnya pendapatan.

b. Penjual yang memiliki pekerjaan tetap sulit untuk menjawab pertanyaan pelanggan yang menanyakan ketersedian sepatu yang menyebabkan pelangan tersebut mengurungkan niatnya untuk membeli di sepokatsepatu.

\section{PENELITIAN SEBELUMNYA}

Menurut penelitian yang berjudul

"Perancangan E-Bisnis pada Toko Alya Gorden Dengan Menggunakan Konsep Content Management System (CMS).[2] Pemasaran Toko Alya ini masih menggunakan sistem manual sehingga konsumennya terbatas. Berkaitan dengan masalah tersebut, pengelolaan konten web secara continue menjadi hal yang sangat penting dalam pengembangan web. Salah satu cara untuk memecahkan permasalahannya yaitu dengan mernerapkan Content Management System (CMS) dengan tujuan untuk memberikan kemudahan bagi pembisnis dalam mengembangkan usahanya agar tercapai dengan tujuan yang diharapkan.

Menurut penelitian yang berjudul "Pemasaran Sepatu Bunut Kisaran Menggunakan Konsep ECommerce”.[3] Kurang luasnya pemasaran sepatu yang berada di sepatu bunut ini yang mengakibatkan toko sepatu yang memproduksi barangnya di daerah sekitar Sumatera Utara ini hanya dapat menjual hasil karyanya tersebut kepada orang yang mampir ke toko sepatu bunut saja. Untuk dapat memasarkannya lebih luas lagi maka akan menerapkan konsep Ecommerce pada Toko Sepatu Bunut Kisaran. Dengan penerapan pemasaran konsep ecommerce ini dapat memasarkan produk sepatu di toko sepatu bunut ini secara lebih luas sampai ke luar negeri agar produk sepatu ini semakin berkembang. Mempermudah serta efektif untuk pelanggan dalam memilih produk, ukuran, model dan harga pada produk sepatunya.

Menurut penelitian dengan judul "Penggunaan Business Model Canvas Pada Perusahaan Customade”.[4] Dalam memulai sebuah usaha dibutuhkan strategi usaha yang matang agar perusahaan yang dijalankan berjalan dengan maksimal. Hal ini yang ingin dilakukan oleh industri 
yang bergerak dibidang fashion yaitu Customade Indonesia. Jika dari awal saat membuat bisnis sudah memiliki model bisnis yang salah dapat menyebabkan kerugian materi serta kehilangan peluang dalam meningkatkan potensi bisnis yang ingin dijalankan. Maka dari itu customade ini menerapkan Bussiness Model Canvas (BMC). Dengan Bussiness Model Canvas (BMC) yang dapat membantu perusahaan untuk melihat lebih akurat atau lebih jelas bagaimana bentuk usaha yang akan dijalani. Serta dapat melihat penjelasan bisnis secara keseluruhan dengan mengisi segmen-segmen yang sudah ada di Bussiness Model Canvas (BMC).

\section{METODE PENELITIAN}

\subsection{Metodologi Pengumpulan Data}

Metode ini saya gunakanan untuk mendapatkan infromasi yang diperlukan untuk mencapai tujuan dari penelitian ini. Berikut ini adalah metode pengumpulan data penelitian yang telah dilakukan penulis yaitu:

\section{a. Wawancara}

Teknik pengumpulan data yang dilakukan melalui tatap muka bersama narasumber. Metode ini dilakukan dengan cara memberi pertanyaan kepada pemilik Sepokatsepatu secara langsung. Melalui metode ini penulis dapat mengetahui bagaimana proses bisnis penjualan pada Sepokatsepatu.

b. Observasi

Teknik pengumpulan data yang dilakukan dengan mengamati langsung. Metode ini dilakukan penulis dengan pengamatan langsung ke Sepokatsepatu dalam memperhatikan proses penjualan.

c. Studi Literatur

Penelitian ini menggunakan studi literatur yang dipilih dari macam-macam refrensi yang sama dengan permasalahan yang diamatin. Studi ini dilakukan melalui jurnal sebagai acuannya dalam melalakukan kegiatan penelitian ini.

\subsection{Teknik Analisis Data}

Teknik analisis data ialah suatu langkah yang harus dilakukan dari sebuah penelitian, karena analisa berfungsi untuk menyimpulkan hasil penelitian, yang dapat mengolah data menjadi informasi, sehingga terdapat karakteristik atau sifatsifat data yang dapat dengan mudah dimengerti dan bermanfaat untuk menjawab masalah-masalah yang berkaitan dengan sebuah kegiatan penelitian.

a. Analisa Sistem

Alat yang digunakan pada kegiatan ini ada activity diagram dan use case diagram. Pada tahap ini yang dilakukan adalah mempelajari dan mengetahui apa saja yang dikerjakan sistem dan mengidentifikasi masalah. b. Analisa Perancangan Sistem

Alat-alat yang digunakan pada kegiatan ini adalah class diagram, rancangan layar dan system sequence diagram. Pada tahap ini dimana akan merancang sistem dengan rinci berdasarkan hasil analisa sistem sehingga akan ada model sistem terbaru yang diusulkan.

\subsection{Bussiness Model Canvas}

Business Model Canvas merupakan sebuah bahasa yang digunakan untuk menggambarkan, mendeskripsikan, menganalisa, dan merancang model bisnis pada suatu perusahaan.[5]

\subsection{Website}

Kumpulan dari berbagai macam halaman situs yang terangkum di dalam sebuah domain atau juga subdomain, yang lebih tepatnya berada di dalam WWW (World Wide Web).[6]

\subsection{Content Management System (CMS)}

CMS (Content Management System) merupakan sebuah sistem yang digunakan untuk mengelola proses pembuatan, pembaruan dan publikasi konten secara seksama, yang menyangkut pada informasi dalam bentuk teks, grafik, gambar maupun dalam bentuk lainnya yang perlu dikelola terlebih dahulu. [7]

\subsection{Wordpress}

Wordpress adalah sebuah perangkat lunak yang digunakan untuk membuat website. Namun tidak hanya web pribadi dan situs berita, tetapi bisa dijadikan toko online. Wordpress ini sudah sangat popular untuk digunakan sebagai layanan blog.[8]

\section{HASIL DAN PEMBAHASAN}

\subsection{Bussiness Model Canvas}

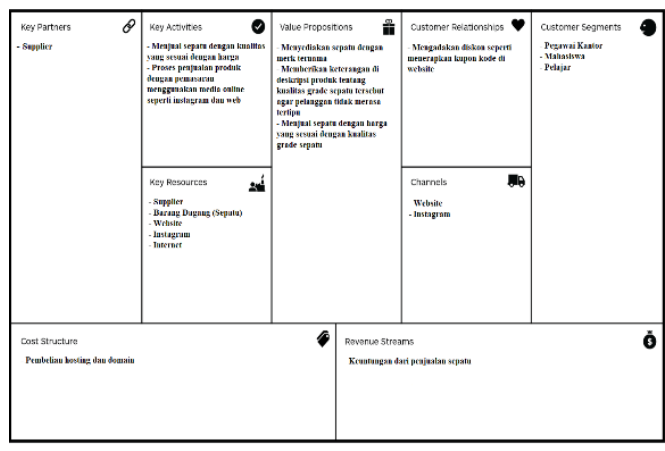

Gambar 1. Bussiness Model Canvas

Gambar 1 ialah business model canvas dari Sepokatsepatu, terdiri dari 9 bagian yang menjelaskan proses bisnis. Yaitu: 
a. Customer Segments

Target konsumen yang menjadi sasaran penjualan pada Sepokatsepatu adalah pegawai kantor, mahasiswa dan pelajar.

b. Value Proposition

Merupakan nilai atau kelebihan yang akan produsen tawarkan kepada konsumen. Menyediakan sepatu dengan merk ternama, memberikan keterangan produk di deskripsi agar pelanggan tidak merasa tertipu dan menjual dengan harga yang sesuai dengan kualitas grade sepatu.

c. Channels

Media atau cara bagaimana produsen dapat menjangkau konsumen. Pemesanan dengan melalui website dan instagram.

d. Customer Relationship

Cara yang akan dilakukan produsen untuk dapat berhubunan dengan konsumen. Sepokatsepatu mengadakan diskon berupa kupon kode.

e. Revenue Streams

Cara produsen untuk bagaimana cara mendapatkan keuntungan dari value proposition. Keuntungan Sepokatsepatu didapat dari hasil penjualan sepatu pemesanan online baik dari website maupun media social.

f. Key Activies

Aktivitas yang berkaitan dengan aktivitas bisnis yang berkaitan dengan sebuah produk dengan menjual sepatu dengan kualitas yang sesuai dengan harganya dan proses penjualan produk dengan pemasaran menggunakan media online seperti instagram dan web.

\section{g. Key Resource}

Sumber daya yang harus dibutuhkan. Sumber daya yang merupakan inti bagi kelangsungan Sepokatsepatu adalah supplier, barang dagangan (sepatu), website, Instagram dan internet.

h. Key Partnership

Pihak-pihak yang bekerja sama dengan produsen dalam upaya untuk memudahkan aktivitas bisnis. Key Partnetships pada Sepokatsepatu ialah supplier.

\section{i. Cost Structure}

Menjelaskan tentang pengeluaran apa saja yang dibutuhkan untuk menjalani bisnis ini. Yaitu Pembelian hosting dan domain.

\subsection{Activity Diagram}

Menurut (S. D. Rachmawati, 2016) Menggambarkan sebuah proses bisnis dan urutan aktivitas dalam sebuah proses. Dipakai pada model bisnis untuk memperhatikan urutan aktivitas prose bisnis. [9]

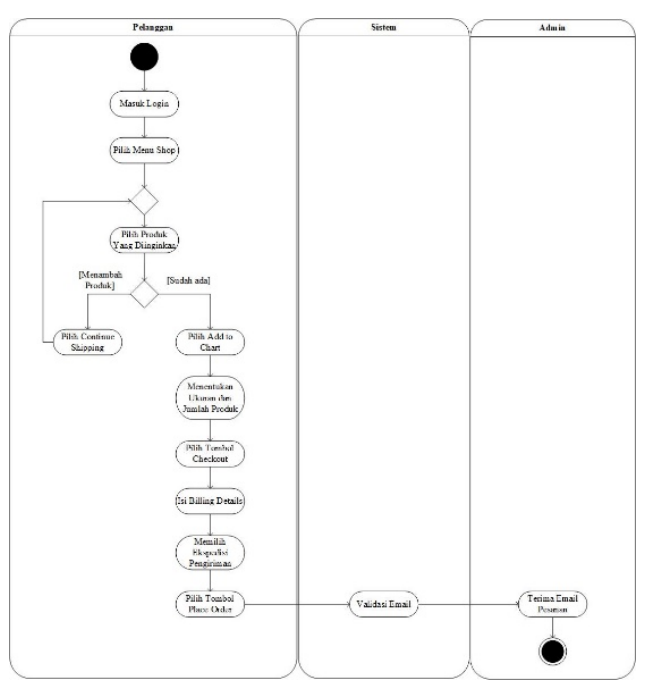

Gambar 2. Activity Diagram Proses Pemesanan

Gambar 2 adalah activity diagram proses pemesanan yang terdapat 3 actor yaitu pelanggan, sistem, dan admin. Aktivitas diawali dengan melakukan login dari pelanggan lalu melakukan pemesanan dan sistem akan memvalidasi email, dan admin akan menerima email pesanan.

\subsection{Use Case Diagram}

Diagram yang menggambarkan fungsionalitas dari sebuah sistem yang akan dilakukan. Use case mempresentasikan sebuah use case mempresentasikan sebuah interaksi antara actor dengan sistem.[9]

\section{a. Use Case Diagram Master}

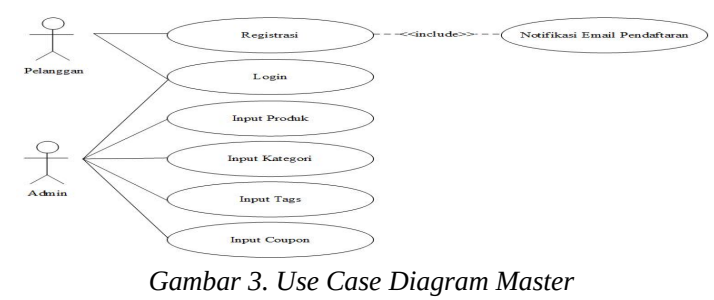

Gambar 3 ialah Use Case Diagram Master, yaitu pelanggan dapat melakukan registrasi kemudian mendapat notifikasi email dari sistem lalu dapat login. Admin dapat melakukan login input produk, kategori, tags dan kupon.

b. Use Case Diagram Transaksi

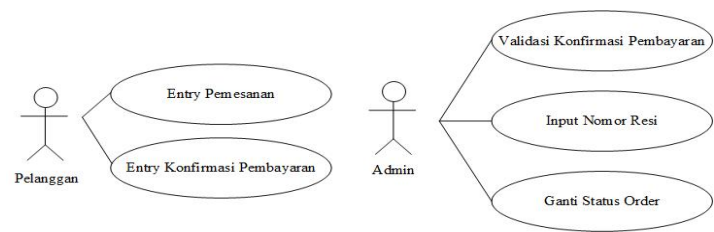

Gambar 4. Use Case Diagram Transaksi 
Gambar 4 ialah use case diagram transaksi, yang terdapat 2 actor didalamnya yaitu pelanggan dan admin, pelanggan akan melakukan pemesanan dan konfirmasi pembayaran, lalu admin akan dapat melakukan validasi konfirmasi pembayaran serta input nomor resi pengiriman dan ganti status order.

c. Use Case Diagram Laporan

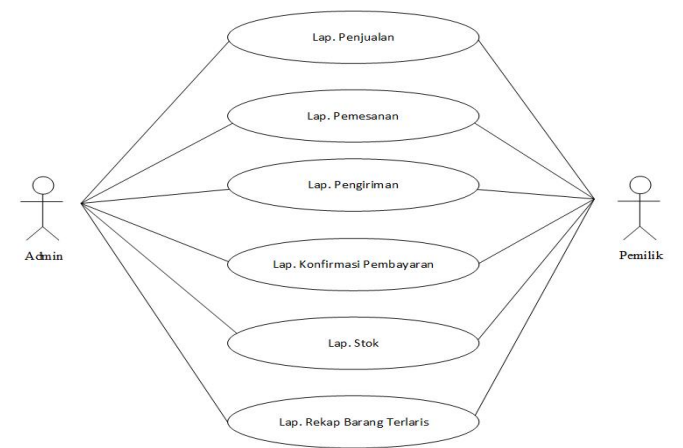

Gambar 5. Use Case Diagram Laporan

Gambar 5 ialah use case diagram laporan. Terdapat 2 actor yaitu admin dan pemilik. Admin dapat mencetak laporan penjualan, laporan pemesanan, laporan pengiriman, laporan konfirmasi pembayaran, laporan stok dan laporan rekap barang terlaris, kemudian memberikan kepada pemilik

\subsection{Class Diagram}

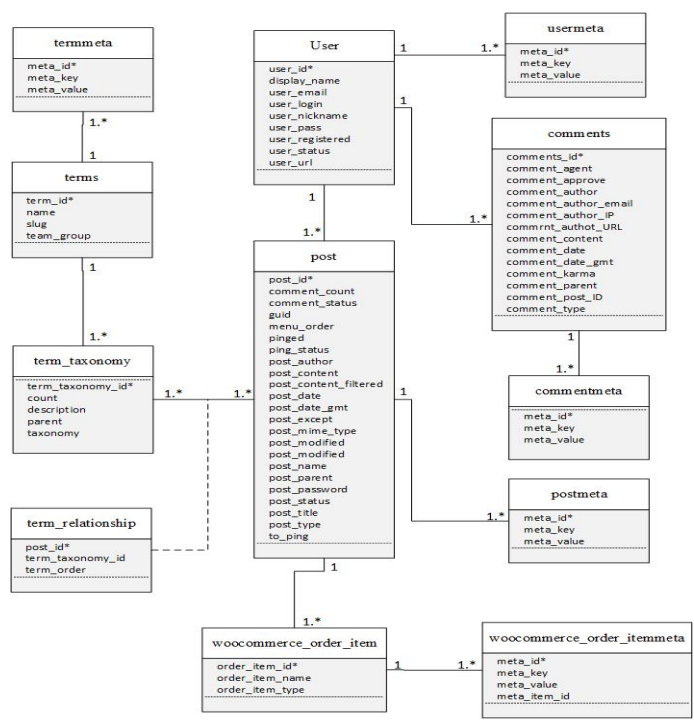

Gambar 6. Tampilan Menu Admin

Gambar 6 merupakan class diagram dari website Sepokatsepatu

\subsection{Struktur Tampilan Menu}

a. Struktur Tampilan Menu Pelanggan

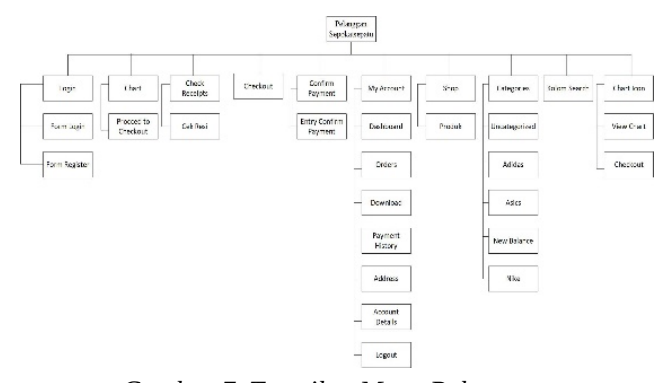

Gambar 7. Tampilan Menu Pelanggan

Gambar 7 merupakan tampilan menu pelanggan di website Sepokatsepatu.

b. Struktur Tampilan Menu Admin

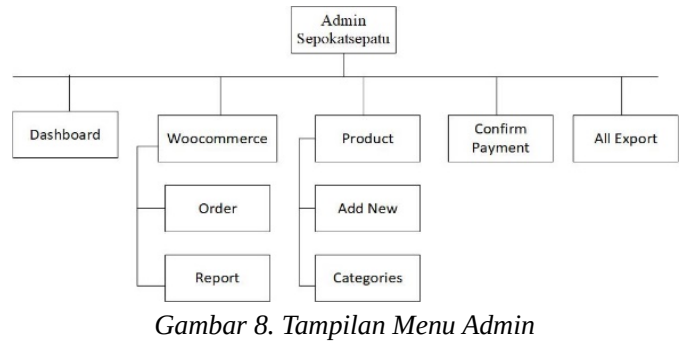

Gambar 8 merupakan tampilan menu admin di website Sepokatsepatu.

\subsection{Rancangan Layar}

a. Rancangan Layar Cart

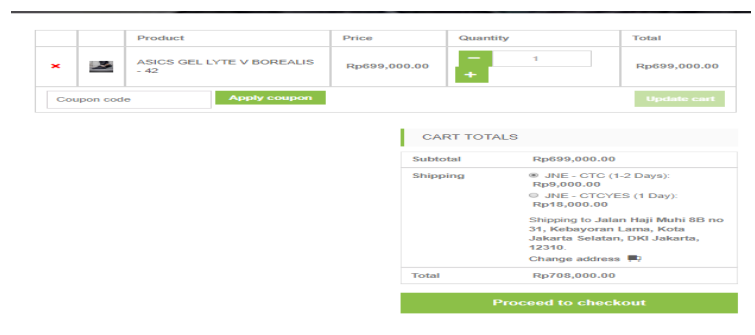

Gambar 9. Rancangan Layar Cart

Gambar 9 merupakan rancangan layar cart yang memperlihatkan produk-produk yang sudah berhasil dimasukkan ke keranjang belanja.

b. Rancangan Layar Produk

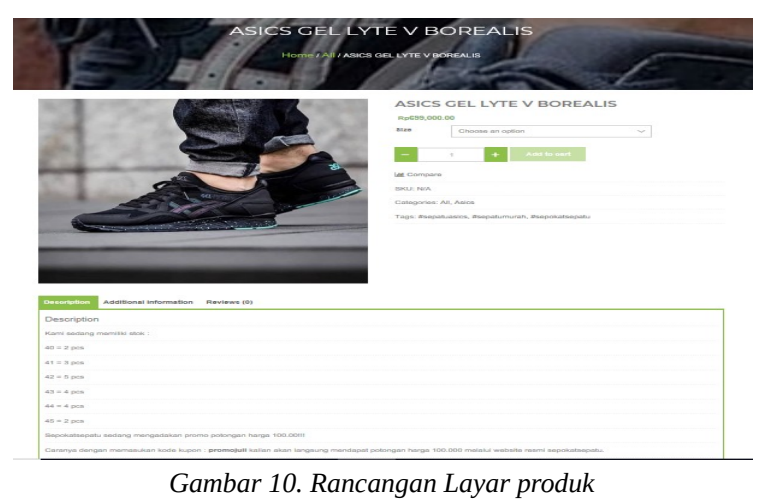


Gambar 10 merupakan rancangan layer produk yang menampilkan ukuran sepatu yang tersedia, tersedia atau tidaknya stok sepatu pada ukuran tertentu dan jumlah sepatu yang dibeli. Juga memperjelasnya di deskripsi produk.

c. Rancangan Layar Confirm Payment

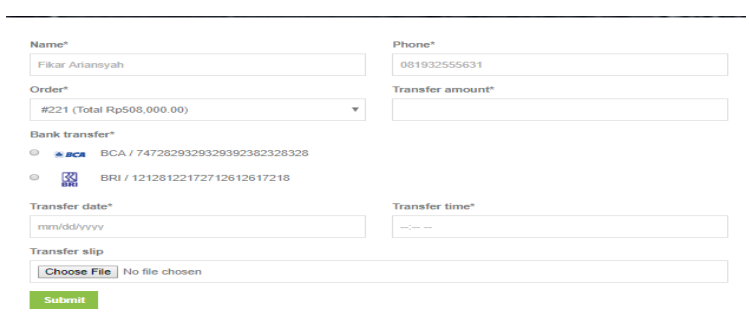

Gambar 11. Rancangan Layar Konfirmasi Pembayaran

Gambar 11 ialah rancangan layar konfirmasi pembayaran yang berisikan kolom nama, nomor telfon, order, jumlah transfer, pilihan bank, tanggal transfer, jam transfer dan upload foto bukti transfer.

\subsection{Keluaran Sistem Usulan}

a. Keluaran Sistem Usulan Email Order Sukses

\section{Thank you for your payment.}

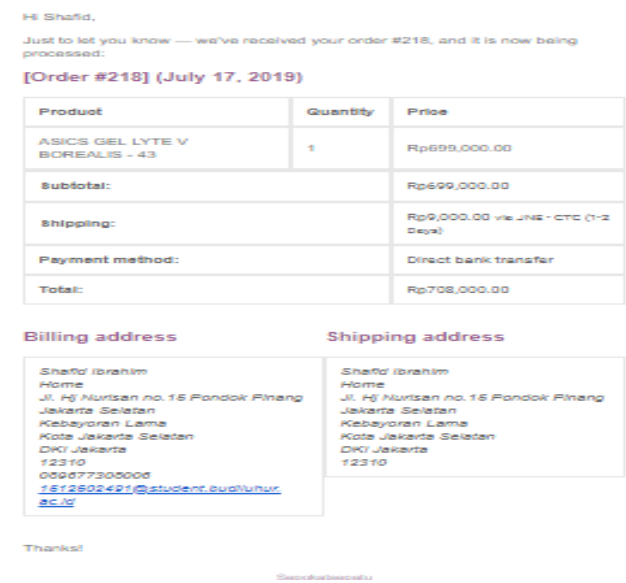

Gambar 12. Keluaran Sistem Usulan Email Order Sukses

Gambar 12 merupakan keluaran sistem usulan email order sukses, email otomatis berubah setelah admin merubah status order menjadi delivered.

\subsection{System Sequence Diagram}

System Sequence Diagram ialah diagram yang dapat digunakan untuk menjelaskan alur informasi input dan output dari sebuah sistem yang terotomatisasi, juga menjelaskan data yang masuk serta data yang keluar dan mengidentifikasi interaksi antara aktor kedalam sistem.[10]

a. System Sequence Diagram Registrasi

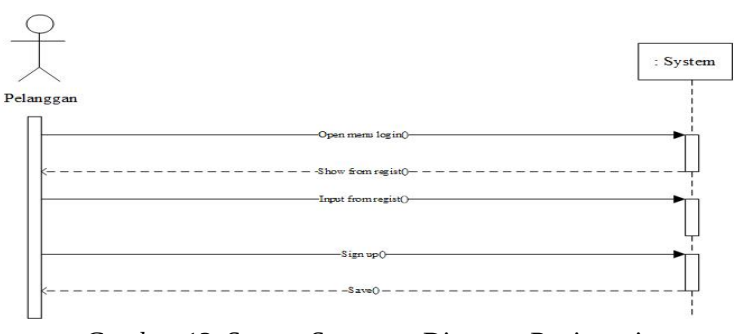

Gambar 13. System Sequence Diagram Registrasi

Gambar 13 merupakan system sequence diagram dari registrasi pelanggan, dimulai dari pelanggan yang masuk ke menu login sampai system menyimpan data pelanggan.

b. System Sequence Diagram Pemesanan

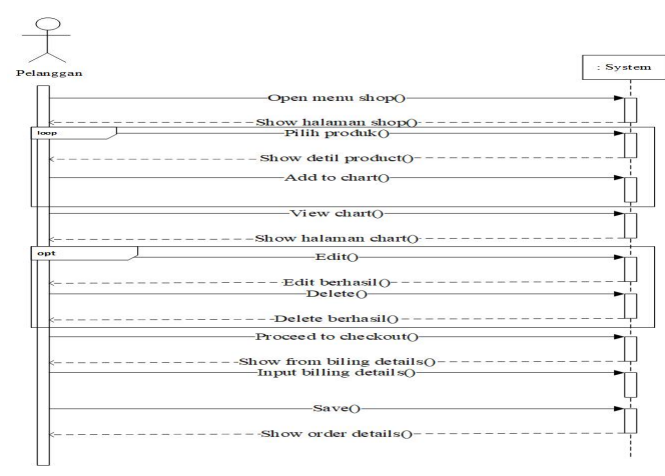

Gambar 14. System Sequence Diagram Pemesanan

Gambar 14 System Sequence Diagram dari pemesanan yang pelanggan memilih menu shop, memilih produk hingga masuk ke halaman chart dan system akan masuk ke order details.

\subsection{Strategi SEO dan Marketing}

Berkut Strategi SEO yang saya gunakan dalam penelitian ini :

a. Install Plugin Yoast SEO

Diawali dengan menginstall plugin Yoast SEO. Yoast SEO merupakan plugin wordpress untuk membantu dalam hal optimasi SEO website yang menggunakan CMS.

b. Aktivasi Google Console

Google console menyediakan laporan berupa data yang dapat membantu bagaimana cara halaman website dapat muncul di hasil pencarian serta dapat mengetahui search query dimana halaman dari website akan muncul di hasil pencarian dan juga dapat mengetahui seberapa sering di kunjunginya.

c. Tambah Title Tag

Dalam SEO, ttle tag sangat penting karena title tag merupakan faktor dasar search engine untuk mengukur relevansi dari keywoard yang dicari pengguna.

d. Tambah Meta Description

Meta Description adalah kesempatan dari pengguna website untuk memasarkan konten kepada 
pencari dan memungkinkan mereka untuk mengetahui halaman tersebut berisi informasi yang sedang mereka cari.

e. Tambah Focus Keyphrase

Difitur ini dapat membantu untuk mengidentifikasi keyword yang akan dioptimasi dan dengan otomatis yoast akan mengubah status on page artikel.

Berikut adalah strategi marketing yang saya gunakan dalam penelitian ini :

a. Mengadakan promo disetiap bulannya yang hanya berlaku di website agar banyak pelanggan yang mengunjungi website.

b. Menyantukan alamat website di profile Instagram Sepokatsepatu.

c. Mengalihkan untuk proses pembelian ke website.

d. Memanfaatkan fitur snapgram pada instagram untuk mempromosikan website

\section{KESIMPULAN}

Dari penelitian dan pembahasan yang dilakukan selama penulisan ini telah dapat diambil kesimpulan sebagai berikut:

a. Dengan adanya website e-commerce berbasis content management system di Sepokatsepatu dapat memudahkan dalam hal menjual produk secara lebih luas,.

b. Menampilkan informasi produk yang lengkap dan menarik bagi pelanggan

\section{DAFTAR PUSTAKA}

[1] Heru, M. M. S. R. S., "Implementasi E-Commerce Sebagai Media Penjualan Online (Studi Kasus Pada Toko Pastbrik Kota Malang)”. Jurnal Administrasi Bisnis (JAB), 2(1), pp. 1-9.2015.

[2] Elinawati, S. \& Muhammad, A., "Perancangan Content Management System (CMS) Dengan Studi Kasus E-Bisnis Pada Toko Alya Gorden”. 2(1).2015.

[3] Azhar, Z., "Pemasaran Sepatu Bunut Kisaran Menggunakan Konsep E-Commerce”. Jurnal Teknologi dan Sistem Informasi (JURTEKSI), 3(1), pp. 11-19.2016.

[4] Natassyah, Z., Hamzah \& Prarendra, I., "Penggunaan Business Model Canvas Pada Perusahaan Customade”. 2(2), pp. 1-7.2015.

[5] Setyorini, R., “Analisis Model Bisnis Pada Eighteen Nineteen Laundry Dengan Pendekatan Business Model Canvas” 1. 1(1), pp. 70-81.2017.

[6] Sugiyanto, Y. \& Musihudin, M., "Sistem Pakar Diagnosis Kualitas Bibit Kambing Pe ( Peranakan Ettawah ) Menggunakan Image Prossesing Berbasis Website".2018.

[7] Elinawati, S. \& Muhammad, A., "Perancangan Content Management System (CMS) Dengan Studi Kasus E-Bisnis Pada Toko Alya Gorden”. 2(1).2015.
[8] Rachmawati, R., “Teknik dan Ideologi Penerjemahan di Wordpress”. Volume 7, pp. 211224.2016.

[9] Rachmawati, S. D., "Sistem Informasi Penjualan Alat Tulis Kantor Berbasis Web Pada CV”. Sumber Rezeki jakarta. Volume 2, pp. 283-288.2016.

[10] Ariefni, D. F. \& Legowo, M. B., "Penerapan Konsep Monitoring dan Evaluasi Dalam Sistem Informasi Kegiatan Mahasiswa di Perbanas Institute Jakarta”. Jurnal Teknik Informatika dan Sistem Informasi, Volume 4, pp. 422-432.2018. 